\title{
Aqueduct Gliosis Caused by Keratin and Cholesterol In a Case of Craniopharyngioma
}

\author{
DIKRAN S. HOROUPIAN, HENRYK M. WISNIEWSKI, ROBERT GAMBLE AND ARIE L. LIEBESKIND
}

\begin{abstract}
SUMMARY: Keratin and cholesterol particles released by a craniopharyngioma were shown to be the agents involved in the production of a foreignbody granulomatous arachnoiditis and ependymitis. Some of the particles were seen embedded in the reactive subependymal glial tissue along the aqueduct of Sylvius. It was thought they were a major factor leading to the aqueductal stenosis. However, we have also considered that the change in cerebrospinal fluid hydrodynamics following the ventriculopleural shunt contributed to the occlusion of the aqueduct.
\end{abstract}

RÉSUMÉ: Il a été démontré que des particules de kératine et de cholestérol liberées à partir d'un craniopharyngiome pouvaient induire une arachnoidite et une épendymite granulomateuse du type réaction à corps étranger. On a pu mettre en évidence des particules enfouies au sein d'une réaction gliale sousépendymaire et ce tout au long de l'aqueduc de Sylvius. De cette constatation, on a déduit que c'etait une cause majeure dans la production de la stenose de l'aqueduc de Sylvius. Cependant, nous croyons que les modifications hydrodynamiques du liquide céphalorachidien engendrées par la dérivation ventriculo-pleurale contribuent à l'occlusion de l'aqueduc de Sylvius.

\footnotetext{
From the Departments of Pathology (Neuropathology), Neurological Surgery, Neuroradiology, and the Rose F. Kennedy Center for Mental Retardation and Human Development, Albert Einstein College of Medicine, The Bronx, New York, U.S.A.
}

Reprint address: Dr. D. S. Horoupian, Dept. of Pathology, Health Science Center, 700 William Ave., Winnipeg, Canada R3E 0Z3.

\section{INTRODUCTION}

It is known that the contents of both craniopharyngioma and intracranial pearly tumors can be irritating to the meninges and can cause either a chemical or "foreign-body" granulomatous leptomeningitis (Gaup, 1942). The effect of these products on the ependymal lining has not been adequately investigated. Zülch (1965) briefly mentioned that they can cause ependymitis and aqueduct gliosis. However, a review of the literature (Bartlett, 1971; Kramer, Southard, and Mansfield, 1968; Love and Marshall, 1950; Matson and Crigler, Jr., 1969; Russell and Rubenstein, 1971) failed to reveal a case in which these complications were documented. The aqueduct was involved in two patients (Grover and Balian-Rorke, 1968: Iyer, 1952), but in both the obstruction was due to direct invasion of the midbrain by the craniopharyngioma.

It is the purpose of this paper to suggest that aqueduct gliosis* may result from ependymitis from the contents of a craniopharyngioma**. The shunting procedure which was performed in the case presented here may have facilitated this process.

\section{Case Report}

A 30-year-old, white, male schoolteacher was admitted to hospital in April, 1970, for evaluation of a progres-

\footnotetext{
*Throughout this paper we have retained the terminology used by Dorothy Russell in her monograph "Observations on the Pathology of Hydrocephalus." SRS 265

** The terms craniopharyngioma and epidermoid cyst of the brain will be used interchangeably, without drawing a rigid distinction between the two types of tumors.
}

sive organic mental syndrome. He was known to have a suprasellar tumor and hydrocephalus. In March, 1967, he had been investigated for left hemicephalgia associated with distortions of visual and auditory perceptions. The neurologic examination then was normal. Skull films displayed a large suprasellar calcification. A left carotid angiogram showed evidence of hydrocephalus, but no tumor stain. A lumbar puncture opening pressure of $240 \mathrm{~mm}$ was recorded. A pneumoencephalogram showed dilated ventricles with air in the sulci over both hemispheres and a deformity in the posterior portion of the third ventricle including the aditus of the aqueduct, sec adary to a suprasellar mass (Figs. 1A ar: $1 \mathrm{~B}$ ). A right ventriculopleural shunt was done. A lumbar puncture done one week later showed an opening pressure of 165 $\mathrm{mm}$, and a protein of $96 \mathrm{mgm} \%$. In August of 1968 he became depressed, had several job changes, and finally quit work in February, 1970, because he had become increasingly forgetful. Physical examination in April 1970 revealed a well-developed man with a bland affect and moderate disorientation indicative of an organic mental syndrome. There was no papilledema. A left superior quandrantanopsia was present. Bilateral horizontal nystagmus, greater on the left, and a mild left seventh nerve paresis were noted. His gait was broad-based, and there was left upper extremity ataxia, but the Romberg test was normal. Sensory and motor examination were normal. There were no pathologic reflexes. The Holter valve was functioning.

Skull films showed the posterior clinoids and dorsum sellae to be more demineralized, and a pneumoencephalogram done April, 1970, failed to show the ventricles. On April 23, 1970, a right frontal craniotomy was performed. The corpus callosum was split, and a large, solid, but partially cystic craniopharyngioma was removed via a 
midline split in the hypothalamus. Postoperatively the patient never regained consciousness and had severe electrolytic disturbances as a part of his diabetes insipidus. In addition, there were several episodes of gram negative and positive sepsis, and he expired in October, 1970, despite vigorous therapy. During his hospital stay, repeated lumbar punctures were performed and the cerebrospinal fluid was always negative for bacteria.

\section{Postmortem Examination of the Brain: (XC-1035)}

The dura and leptomeninges underlying the right frontal craniotomy were thickened. The shunt catheter was patent and protruding from the surface of the right occipital lobe. Part of the floor

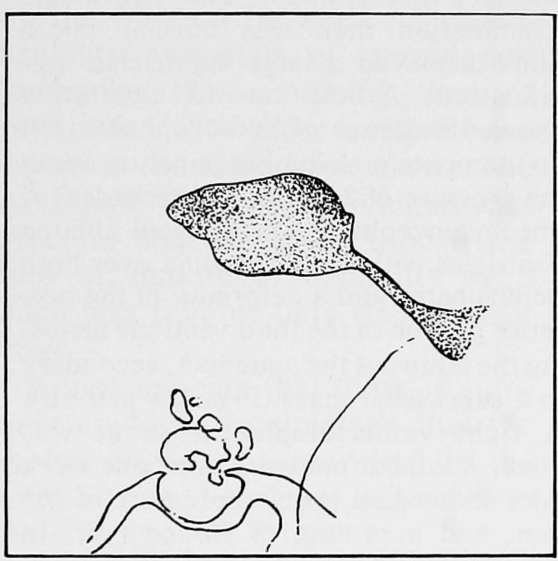

Figure $1 B$. A line drawing traced from the radiograph (Fig. 1A) depicts the aqueduct deformity.

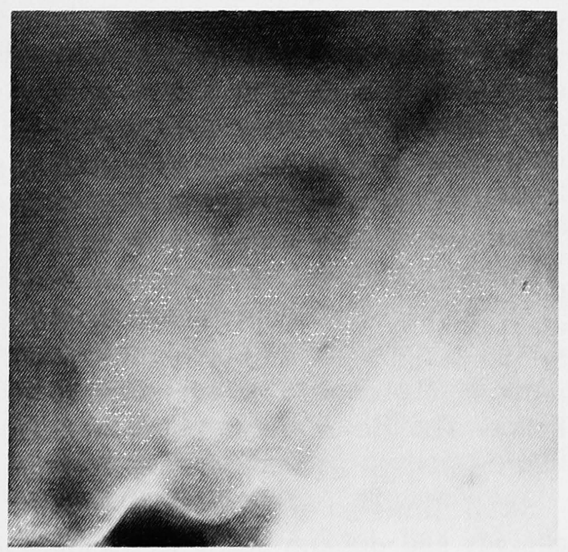

Figure IA. Pneumoencephalogram shows patency of the aqueduct. The posterior portion of the IIIrd ventricle and the aditus of the aqueduct are deformed by the superior and posterior extension of a suprasellar calcified mass. of the third ventricle was absent and the mammillary bodies were not visualized. A firm, gritty, irregular nubbin measuring $0.6 \mathrm{~cm}$ protruded from the left wall of the third ventricle. An operative defect measuring $2.5 \mathrm{~cm}$ was situated in the genu of the corpus callosum; the anterior fornix and the lamina terminalis were partially disrupted. The proximal segments of the anterior cerebral and the left middle cerebral arteries were buried in dense arachnoid adhesions, and only the right middle cerebral artery was free of adhesions.

Coronal sections of the brain revealed dilated ventricles. The ventriculostomy was patent. There were multiple old infarctions, the most conspicuous was along the territorial supply of the right anterior cerebral artery. The anterior fornix was ragged and partially infarcted. The walls of the third ventricle were excavated and yellow-stained. Sections of the brain stem disclosed total obliteration of the rostral segments of the aqueduct of Sylvius (Fig. 2). The aqueduct narrowing extended to the rostral segment of the pons.

\section{Microscopic Examination:}

The nubbin seen protruding from the wall of the third ventricle was fairly well encapsulated and was filled with laminated keratin mixed with amorphous eosinophilic material. A few calcospherites and many cholesterol clefts appeared close to the capsule. At the periphery of the lesion some of the more

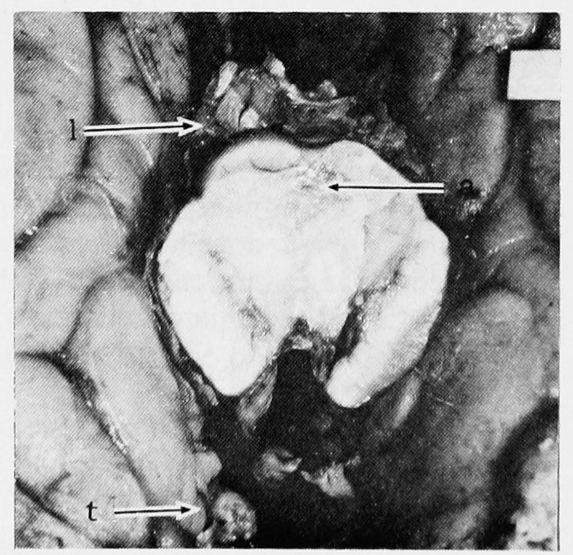

Figure 2. Horizontal cut through the midbrain showing aqueduct occlusion (a). The floor of the IIIrd ventricle is absent and a nubbin of tissue $(t)$ is seen projecting from the left wall of the IIIrd ventricle. The leptomenings (1) are thickened. viable mural cell nests formed irregular serpiginous lamellae that intertwined with keratin whorls (Fig. 3). Islets of keratin containing tumor tissue were present in the necrotic wall of the third ventricle in the remnants of the anterior fornix and in the posteromedial nucleus of the left thalamus. Keratin and cholesterol particles were also seen in the subarachnoid space especially in the interpeduncular fossa and were associated with an intense foreign-body granulomatous reaction and fibrosis of the leptomeninges (Figs. 4 and 5). Many hemosiderocytes and sometimes multinucleate macrophages were seen enmeshed in the thickened arachnoid

Transverse sections through various levels of the aqueduct showed maximal

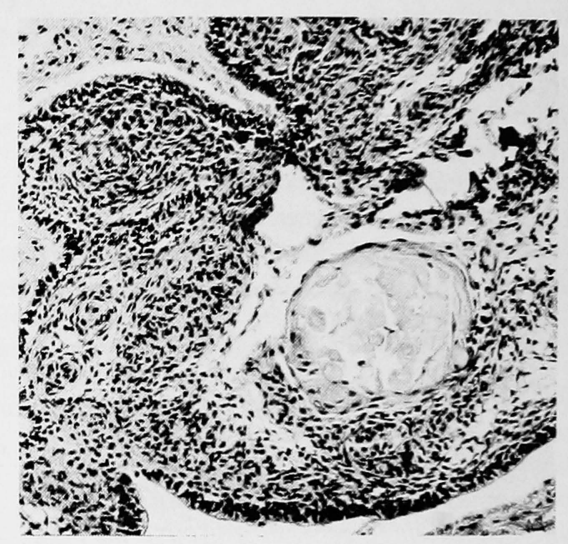

Figure 3. The mural tissue of the nubbin shown in (Fig. 2) is composed of serpiginous lamellae of cells with perpipheral palisading and nests of keratin. (Hematoxvlin-eosin X130)

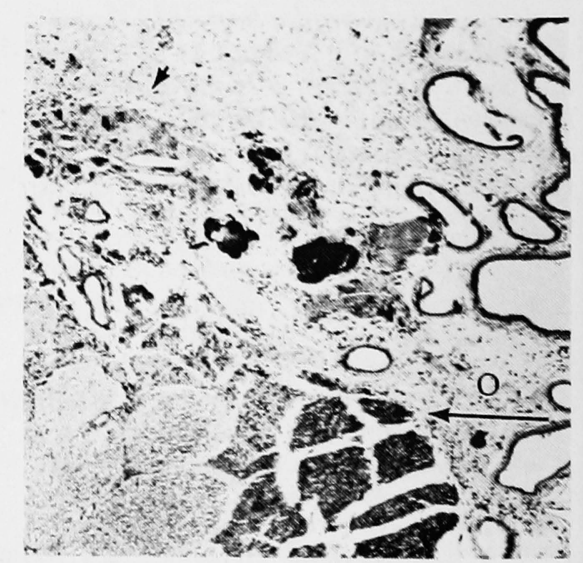

Figure 4. Extensive leptomeningeal adhesions and foreign-body granulomata in the interpeduncular space at the level of the occulomotor nerve (o). (Hematoxylin-eosin X35) 


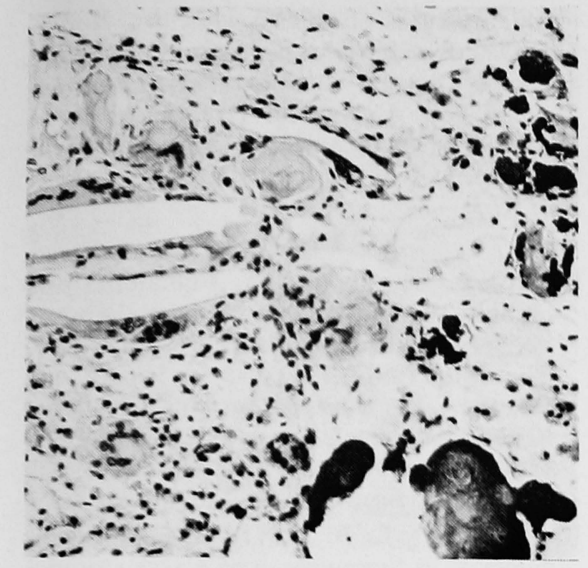

Figure 5. The foreign-body granulomatous reaction as indicated by the arrow-head in (Fig. 4) contains abundant giant cells with cholesterol clefts, keratin particles and obvious calcification. (Hematoxylin-eosin X375)

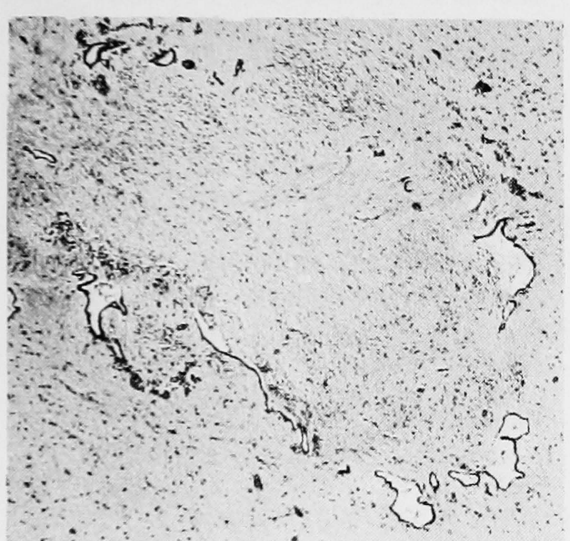

Figure 6. Rostral aqueduct is totally obliterated by glial tissue with sequestered islets of ependymal cells forming "aqueductules." (Hematoxylineosin X38)

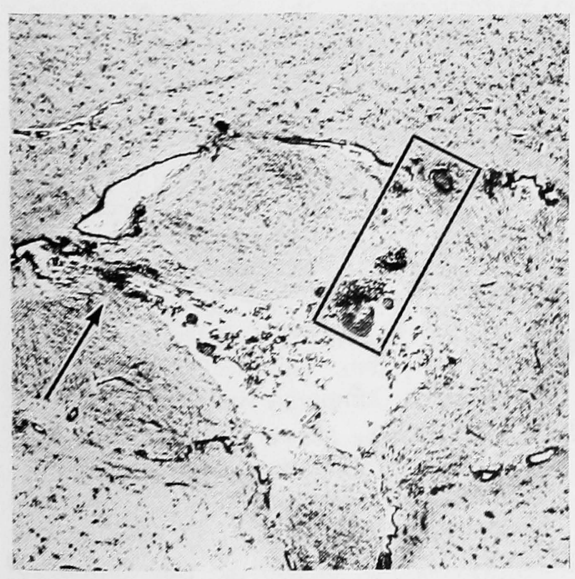

Figure 7. Caudal aqueduct is partially occluded by exuberant glial granulations. (Hematoxylin-eosin X38) disorganization of the lumen at the point of obliteration. This region was occupied by dense fibrillar gliosis in which a few "aqueductules" lined with ependymal cells had replaced the original aqueduct (Fig. 6). More caudally, the lumen was surrounded by a feltwork of glial tissue of variable density. In some sections, keratin and cholesterol particles were clinging to the aqueduct lining (Figs. 7 and 8), and were eliciting some inflammatory reaction.

The exudate was formed mainly of lymphocytes, monocytes and multinucleate r.acrophages. Keratin was also entrapped by exuberant glial tongues and whenever a keratin particle was seen embedded in the glial tissue it was surrounded by a rosette of nuclei (Fig. 9). It was difficult at times to determine whether these nuclei belonged to "sequestered" ependymal cells or were those of a foreign-body multinucleate giant cell. Pronounced sub-ependymal gliosis was present in fourth ventricle and its foramina were almost totally covered with a dense web of glial tissue. Keratin particles were occasionally seen either free in the cavity of the fourth ventricle or surrounded or engulfed by multinucleate foreign-body giant cells.

The choroid plexus of both lateral ventricles contained a few lymphocytes, but there was no evidence of foreign-body granulomatous reaction. The choroid epithelium was apparently well preserved and there was no indication of flattening of its cuboidal cells.

\section{DISCUSSION}

Aqueduct obstruction seems to be an infrequent complication of all intracranial keratin-containing tumors, craniopharyngioma included. In the few reported cases the obstruction was attributed either to compression (Olivecrona and Tönnis, 1967) or invasion (Grover and Balian-Rorke, 1968; Iyer, 1952) of the aqueduct of Sylvius by the tumor. The literature is vague concerning the association of aqueduct gliosis and the release of the contents of these tumors. The shedding of cellular debris (Bagley, 1929) into the brain cavities is known to induce a variable degree of ependymitis and/or arachnoiditis, depending on the nature of the material spilled in the cerebrospinal fluid. It is also known that the content of keratinizing tumor (dermoids, epidermoids, etc.) can be highly irritative and may cause aseptic inflammatory reaction in many tissues in which they rupture (peritoneum, subcutaneous tissue, etc.). However, the extent of a similar reaction occurring in the ventricular lining has received only a limited documentation. It is uncertain whether the cholesterol crystal or the keratin particle is the more irritating element. The former, considered to be derived from keratin, is held most responsible for the irritative action (Russell and Rubinstein, 1971).

In the present case, section of the

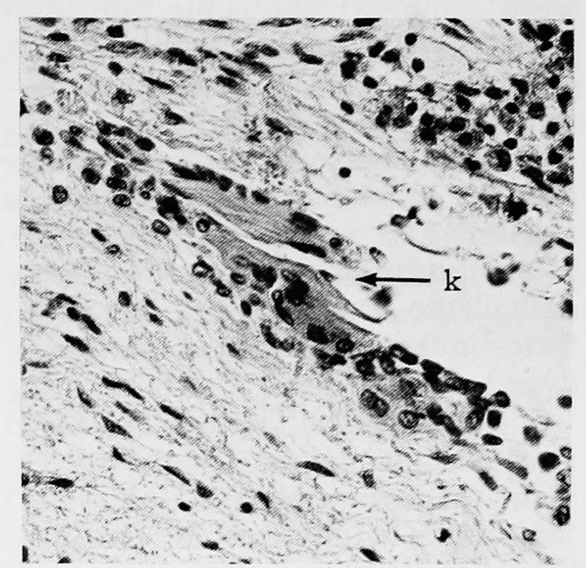

Figure 8. Higher magnification of the area indicated by the arrow in (Fig. 7) displays keratin particles with intercellular bridges, clinging to the ependymal lining. $\mathrm{K}=$ keratin. (Hematoxylin-eosin X460)

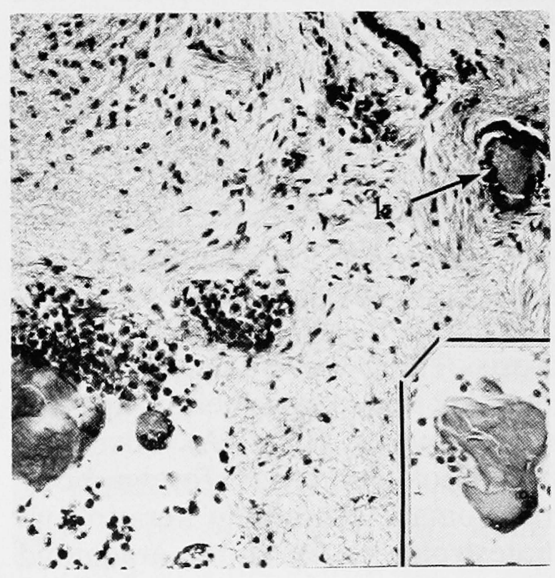

Figure 9. Part of the area outlined by the rectangle in (Fig. 7) shows keratin particles with inflammatory cells in the cavity. The arrow indicates keratin embedded in reactive glia with a rosette of nuclei intervening. (Hematoxylin-eosin X300). Insert shows a giant macrophage in the process of engulfing (or releasing) keratin. 
brain stem showed cholesterol crystals and keratin particles released by the tumor lying within the lumen of a gliotic aqueduct of Sylvius. Also, pieces of keratin were seen in various stages of entrapment by the exuberant glial "stars" prior to being incorporated in the gliotic wall. In addition, inflammatory exudate including foreign-body giant cells was associated with these particles.

These findings suggested that the contents of the craniopharyngioma were mainly responsible for the ependymitis and the subependymal gliosis that followed. Sepsis was improbable since the cerebrospinal fluid obtained for bacteriological examination on repeated occasions was sterile. The reaction excited by bleeding during the operation was difficult to exclude as a possible factor in the production of the ependymal granulations.

It is to be noted that Scarff (1941) advocated a method for the treatment of craniopharyngioma by "marsupializing" the tumor into the lateral ventricle, to allow the cerebrospinal fluid to wash out the contents as they formed. He did not describe ependymitis or aqueduct gliosis complicating these cases. However, this type of surgical approach has not gained popularity and detailed autopsy documentation on cases treated by this procedure is lacking.

If we were to assume that ependymitis and aqueduct gliosis did not complicate Scarff's cases, it is possible that the ventriculo-pleural bypass performed in our case played a significant role in causing the gliosis. There was no doubt that the aqueduct was patent before instituting the bypass (Fig. 1A). Also, the finding of numerous foreign-body granulomata containing keratin and cholestrol particles in the arachnoid along with prominent leptomenigeal fibrosis at the base of the brain suggested that a communicating hydrocephalus existed before the effective shunting was instituted. This cholesterol particles in the arachnoid, along with prominent leptomenigeal fibrosis at the base of the brain, suggested that a communicating hydro- cephalus existed before the effective shunting was instituted. This assumption was further supported by the drop in the lumbar puncture opening pressure from $240 \mathrm{~mm}$ to $165 \mathrm{~mm} \mathrm{H}_{2} \mathrm{O}$ after the bypass procedure. Therefore, it seems logical that the diversion of the cerebrospinal fluid, although helping to reduce the intraventricular pressure, interfered with the hydrostatic dilating effect of the cerebrospinal fluid on the aqueduct. This allowed the tumor particles to stagnate in the aditus of the aqueduct of Sylvius (where the gliosis had totally obliterated the cavity) and in the aqueduct canal. It is likely that the prolonged contact of the particles with the ventricular lining promoted a severe reaction resulting in obliteration of the lumen. Also, in follow-up air studies Foltz and Shurtleff (1966) have demonstrated that during prolonged ventricular shunting for communicating hydrocephalus, aqueductal gliosis developed in approximately twelve of their patients.

The clinical implication of this pathological finding was considered to be significant. By-pass procedures are often used in cases of keratin containing tumors, either as a palliative measure to relieve the increased intraventricular pressure, or ancillary to a more direct drastic approach to the tumor. In the latter event, both granulomatous ependymitis and arachnoiditis are prone to complicate the operation, as demonstrated in the present case. Aqueduct gliosis is expected to occur in these cases, if the shunt is draining efficiently and there is less fluid pressure in the ventricles to clear the aqueduct of the cholesterol and keratin particles. Therefore any future revision of the shunt should be carefully planned to avoid a sudden rise in the intraventricular pressure.

\section{ACKNOWLEDGEMENTS}

The authors wish to thank Dr. R. D. Terry, Chairman of the Department of Pathology, and Dr. M. P. Valsamis, Chief Diagnostic Neuropathologist, and Dr. K. Shulman, Professor of Neurological Surgery, for their constructive criticism.

Part of this work was supported by grants Nos. NS-02255 and NS-93356 from the Na- tional Institutes of Health while Dr. Horoupian was on sabbatical leave from the Health Sciences Centre, Winnipeg. The present address of Dr. Horoupian is Department of Pathology, Health Sciences Centre, 700 William Avenue, Winnipeg, Manitoba, Canada R3E 0Z3.

\section{REFERENCES}

BAGLEY, C., Jr. (1929). Functional and organic alterations following the introduction of blood into the cerebrospinal fluid. The Intracranial Pressure in Health and Disease. An Investigation of The Most Recent Advances. Research Publications of the Association for research in nervous and mental disease, 8, 217-25.

BARTLETT, J. F. (1971). Craniopharyngioma - A Summary of 85 Cases. Journal of Neurology, Neurosurgery and Phychiatry, 34, 37-41.

FOLTZ, E. L.; and SHURTLEFF, D. B. (1966). Conversion of communicating hydrocephalus to stenosis or occlusion of the aqueduct during ventricular shunt. Journal of Neurosurgery, 24, 520-9.

GAUPP, , R. (1942). Ein teratom im seitenventrikel. Nervenarzt, 15, 363-73.

GROVER, W. D.; and BALIANRORKE, L. (1968). Invasive craniopharyngioma. Journal of Neurology, Neurosurgery and Psychiatry, 31, 580-2.

IYER, C. G. S. (1952). Case report of an adamantinoma present at birth. Journal of Neurosurgery, 9, 221-8.

KRAMER, S.; SOUTHARD, M.; and MANSFIELD, C. M. (1968). Radiotherapy in the management of craniopharyngiomas. Further experiences and late results. American Journal of Roentgenology, 103 44-52.

LOVE, J. G.; and MARSHALL, T. M. (1950). Craniopharyngiomas (pituitary adamantioma). Surgery, Gynecology and Obstetrics, 90, 591-601.

MATSON, D. D.; and CRIGLER, J. F., Jr. (1969). Management of craniopharyngioma in childhood. Journal of Neurosurgery, 30, 377-90.

OLIVECRONA, H.; and TONNIS W. (1967). Klinik und behandlung der raumbeengenden intrakraniellen prozesse. Handbuch der Neurochirurgie. IV/4. Springer-Verlag, Berlin, pp. 272.

ROSS RUSSELL, R. W.; and PENNYBACKER, J. B. (1961). Craniopharyngioma in the elderly. Journal of Neurology Neurosurgery and Psychiatry, 24, 555-64.

RUSSELL, D. S.: and RUBINSTEIN, L. J. (1971). Pathology of Tumors of the Nervous System. Third Edition. Williams and Wilkins Company, Baltimore, pp. 19.

SCARFF, J. E. (1941). A new method for treatment of cystic craniopharyngioma by intra-ventricular drainage. Archives of Neurology and Psychiatry, 46, 843-67.

ZÜLCH, K. J. (1965). Brain Tumors, Their Biology and Pathology. [Translated by A. B. Rothballer]. Second Edition. Springer Publishing Company, Inc.; New York, pp. 244. 